\title{
Humor y registros lingüísticos: un análisis de las columnas Cuarentena en la España vacía, de Daniel Gascón
}

\section{Humour and linguistic registers: an analysis of the press columns Cuarentena en la España vacía by Daniel Gascón}

\author{
Maㅡ Elena Gómez Sánchez \\ Universidad Europea de Madrid, Madrid, España \\ elena.gomez@universidadeuropea.es
}

A la memoria de Ana $M^{a}$ Vigara
con quien tanto reía

A. ACCESO ABIERTO / OPEN ACCESS

Cita: Gómez Sánchez, Maㅡ Elena (2020). Humor y registros lingüísticos: un análisis de las columnas Cuarentena en la España vacía, de Daniel Gascón. Textos en Proceso, 6(2), pp. 37-50. https://doi.org/10.17710/tep.2020.6. 2.4egomez

Editoras: Susana Guerrero Salazar y Carmen Marimón Llorca

Recibido: $31 / 10 / 2020$

Aceptado: 20/11/2020

Conflicto de intereses: La autora ha declarado que no posee conflicto de intereses.

Copyright: () Ma Elena Gómez Sánchez. Esta obra está bajo licencia Creative Commons Reconocimiento 4.0

\section{Resumen}

En agosto de 2020, concretamente entre los días 7 y 12 de ese mes, Daniel Gascón, escritor, director en España de la revista Letras libres y columnista del diario $E l$ País, publicaba en este último medio una serie de seis relatos sobre las aventuras de Enrique Notivol, el protagonista de su novela Un hipster en la España vacía, publicada en junio de 2020 por la editorial Random House. En este trabajo analizaremos desde la perspectiva del análisis del discurso esos seis relatos, seis columnas literarias, con el objetivo de desentrañar algunos de los mecanismos lingüísticos que ponen de manifiesto su sentido humorístico (entre los que se incluyen también referencias explícitas a conceptos lingüísticos), así como los registros empleados por los distintos personajes que aparecen y que contribuyen a caracterizarlos, para llevar a cabo una reflexión sobre determinados imaginarios lingüísticos y el modo en el que estos pueden encontrarse en la prensa.

Palabras clave: humor, prensa, columnas literarias, recursos lingüísticos.

\begin{abstract}
Between August 7th and 12 ${ }^{\text {th }}$ 2020, Daniel Gascón, writer, editor in Spain of the magazine Letras Libres and columnist in the newspaper El Pais, published on the latter six texts on the adventures of Enrique Notivol, the main character of his novel Un hipster en la España vacía (published by Random house in June 2020). With the tools provided by discourse analysis, our aim is to analyse those six literary
\end{abstract}


columns, focusing on some of the linguistic mechanisms that characterize their humoristic approach (among which some specific references to linguistic concepts) appear, as well as on the registers used by the characters, in order to study some linguistic imaginaries and the way in which they can appear on newspapers.

Keywords: humor, newspapers, literary columns, linguistic resources.

\section{Introducción: Las columnas literarias y el humor como elemento para la caracterización de registros lingüísticos}

El objeto de este trabajo es el análisis de seis textos publicados por Daniel Gascón en el diario El País entre el 7 y el 12 de agosto de $2020^{1}$. Se trata de columnas, no de opinión, sino literarias, publicadas en un periódico de tirada nacional, en lo que consideramos como un buen ejemplo de transfuncionalidad, entendiendo esta como "el intercambio de funciones de discursos o de partes de discursos, que pueden funcionar bien como discursos de clases distintas de la propia, bien pueden ser insertos en discursos de otras clases diferentes de aquella a la que pertenecen" (Ruiz de la Cierva, 2012, p. 1). En efecto, si bien el medio en el que nuestro objeto de estudio aparece es periodístico, su contenido es ficcional y su estilo es puramente literario. En este sentido, las columnas que aquí vamos a analizar podrían encajar en la siguiente conceptualización: "La columna, encallada entre el periodismo y la literatura, es un género más bien atípico o incluso paradójico, y que debe respetar ciertas limitaciones que también contribuyen a definirla: la dimensión, la ubicación fija en determinada página del periódico, la temática y la frecuencia. Pero más allá de estos parámetros, el columnista es libre para escribir lo que estime conveniente" (López Hidalgo, 2008, p. 160). O, en palabras de M. a Jesús Casals, "Una de las características de la columna es que importa tanto la expresión como su contenido. La forma y el fondo. Y que es un producto literario para el consumo de masas: es decir, de un público muy amplio y que lee con prisas. [...] La columna [...] también puede ser un análisis personal [...]. O un entretenimiento literario" (Casals, 2000, p. 33). En definitiva, podría afirmarse que estas columnas responden a lo planteado por Teodoro León Gross cuando señala que "la escritura literaria supone hacer literatura pero no 'en' la Literatura sino igualmente 'desde' otra actividad comunicativa, en este caso el Periodismo...”. (León Gross, 2005, p. 7).

La ficción presente en estas columnas se encuentra ya en el fragmento que les sirve de presentación, publicado el 7 de agosto, y en el cual se indica quién es su protagonista. Si bien este resultará familiar a los lectores de la novela Un hipster ${ }^{2}$

\footnotetext{
${ }^{1}$ El modo en que el diario El País presenta esos textos es el siguiente: "Daniel Gascón, autor de Un hipster en la España vacía, inicia una serie de seis relatos sobre el confinamiento en La Cañada, donde Enrique Notivol ha ido a buscar la autenticidad y la comunión con la naturaleza".

2 "The hipster is frequently cast as a young 'creative' person who is part of the middle-class fraction of cultural intermediaries” (Le Grand, 2020, p. 195).
} 
en la España vacía - pues es el mismo³-, esa presentación ofrece también un marco a aquellos lectores que se acerquen a sus andanzas por primera vez en estos textos ${ }^{4}$ :

Desencantado de la vida moderna y ansioso por encontrar la autenticidad y la comunión con la naturaleza, Enrique Notivol se refugia en La Cañada, el pueblo de su tía. Tiene grandes planes para la recuperación de la España vacía, como huertos colaborativos, gallineros no heteropatriarcales y talleres de nuevas masculinidades, y de paso le gustaría olvidar a su exnovia. Los habitantes del pueblo se han acostumbrado a su presencia y hasta lo han hecho alcalde. Desde ese puesto de responsabilidad debe hacer frente a problemas globales y locales: la pandemia amenaza el mundo tal y como lo conocemos, y no está claro que este verano pueda celebrarse el ciclo de homenaje de Agnès Varda en el frontón.

Ya en esta presentación pueden apreciarse algunos de los rasgos fundamentales que, desde un punto de vista lingüístico, van a caracterizar a estas columnas, no solo como literarias, sino fundamentalmente como humorísticas (rasgos, dicho sea de paso, también presentes en la mencionada novela): las hipérboles (se encuentra ansioso, tiene grandes planes, la pandemia amenaza el mundo tal y como lo conocemos), el empleo de un léxico valorativo y "abarcador" cuando no grandilocuente (encontrar la autenticidad y la comunión con la naturaleza, hacer frente a problemas globales y locales), los contrastes en el modo de presentar el estado de ánimo del protagonista y sus actitudes (desencantado y ansioso; grandes planes para la recuperación de la España vacía y de paso olvidar a su exnovia), etc. Para nuestros propósitos, tendremos también en cuenta la reflexión de Ana M. ${ }^{a}$ Vigara (1994, pp. 20-21) cuando señala que "cuando se utiliza como forma concreta de comunicación para la interacción lúdica, el humor se comporta como un estímulo que se basa en el manejo de resortes intelectuales y que precisa de una cierta complicidad afectiva entre los comunicantes para cumplir su cometido: producir una respuesta fisiológica y psíquica, estereotipada y predecible (la risa o la sonrisa)".

En los epígrafes siguientes iremos analizando algunas de las marcas e indicadores ${ }^{5}$ humorísticos que, mediante las elecciones lingüísticas presentes en este conjunto de textos, sirven para caracterizar -entre otros aspectos y con ese sentido- rasgos de una determinada jerga urbana (la del hípster) frente a un habla rural (la del resto de personajes), referencias explícitas a conceptos lingüísticos que contribuyen a la construcción de la autoimagen ${ }^{6}$ del narrador, etc. Y todo ello

\footnotetext{
${ }^{3}$ Antes de la publicación de la novela, ya habían podido leerse algunas de sus primeras páginas en la revista Letras Libres. Y, aunque este no sea el lugar apropiado para una descripción extensa, sí queremos al menos anotar que tanto las columnas que aquí analizamos como la mencionada novela se insertan en una tradición literaria de la que podemos encontrar distintos ecos, los cuales abarcan desde el Menosprecio de corte y alabanza de aldea, de fray Antonio de Guevara, hasta el idealismo un tanto quijotesco (y posmoderno) del protagonista, Enrique Notivol, frente a la visión más realista y sanchopancesca de otros personajes del pueblo, como es el caso de Tomás.

${ }^{4}$ Como señala López Pan (2011, p. 53), "El columnista se inserta en el sistema de los medios, en un periódico que ya ha sido seleccionado por un número de lectores que forman una comunidad intelectual, y comparten en buena medida las preferencias políticas y morales". Creemos que esta frase encaja perfectamente con el caso que nos ocupa, pues es previsible que buena parte de los lectores de las columnas que aquí analizamos conozcan ya previamente, bien a su protagonista, bien a su autor.

${ }^{5}$ Como indica Ruiz Gurillo (2014, p. 150), "las marcas ayudan en la interpretación humorística a los lectores/oyentes; los indicadores constituyen procedimientos de por sí humorísticos".

${ }^{6}$ Respecto a los conceptos de autoimagen y actividades de autoimagen, seguimos a Hernández Flores (2006, p. 638) cuando señala que "se refiere al comportamiento comunicativo con una repercusión positiva o negativa sobre la imagen de uno mismo, es decir, sobre la imagen del hablante, quedando la del destinatario fuera de los efectos de este comportamiento".
} 
teniendo en cuenta, como señala Leonor Ruiz Gurillo (2019, p. 185), que "la inferencia de que el discurso se inscribe en el modo humorístico es clave para la adecuada comprensión del humor".

\section{Referencias lingüísticas explícitas: parodia política y actividades de autoimagen}

En los primeros párrafos del texto con el que comienza la serie leemos lo siguiente:

1) DEL CUADERNO DEL HIPSTER. 1.

La pandemia de la covid-19 ha llegado a La Cañada de Azcón. Si la luz eléctrica o el agua corriente tardaron décadas en venir, esto ha llegado a la vez que en todas partes. Podía interpretarse como un ejemplo de la velocidad de la enfermedad y de las medidas para combatirla, o como la confirmación de que el progreso a veces se hace esperar pero el atraso siempre llega puntualmente.

Por supuesto, no se podía saber. ¿Cómo íbamos a prever, cuando estábamos buscando pronombres válidos para los nuevos géneros que, aunque fueran comprensibles en castellano, tuvieran una clara derivación desde el aragonés y conservaran ecos del catalán, como otras lenguas que quizá se habían hablado en la zona, que una epidemia trastocaría todos nuestros planes? También es mala suerte. Teníamos grandes planes y llegó el microorganismo. Ahora mismo está todo en el aire, incluyendo el ciclo de homenaje a Agnès Varda que íbamos a hacer en el frontón antes de fiestas.

(7 de agosto de 2020)

En el segundo párrafo de este primer ejemplo, escrito en primera persona de plural, que actúa como una suerte de "monólogo interior" del protagonista -en tanto que forma parte de una entrada de su cuaderno, casi como un diario-, encontramos ya una "declaración de intenciones" en cuanto a la preocupación lingüística del personaje. La referencia a esos "pronombres válidos para los nuevos géneros, [que] tuvieran una clara derivación desde el aragonés y conservaran ecos del catalán, como otras lenguas que quizá se habían hablado en la zona" supone una parodia ${ }^{7}$ de determinadas posturas políticas que hacen bandera de la importancia de tener un sistema lingüístico propio como elemento cohesionador ${ }^{8}$. La idea paródica se refuerza por la marca de "quizá" : ni siquiera es seguro que se hubieran hablado en la zona, pero en cualquier caso se considera necesario ese nuevo sistema como elemento identitario (en lo cual encontramos también una actividad de autoimagen, cfr. Hernández Flores, 2006): como alcalde, Enrique se preocupa por encontrar factores que aglutinen a los vecinos. El contraste de abordar esa tarea lingüística (uno de los "grandes planes", junto al ciclo de homenaje a Agnès Varda) con la realidad "poco glamurosa" que supone la epidemia, provocada además por algo muy pequeño ("llegó el microorganismo") refuerza el planteamiento cómico.

\footnotetext{
7 Para este concepto, y junto a la definición que de parodia ("imitación burlesca") ofrece el Diccionario de la lengua española (DLE, en adelante) de la Real Academia Española, nos interesa también la aproximación de Rossen-Knill y Henry (1997, p. 721): "Verbal parody involves a highly situated, intentional, and conventional speech act which re-presents the object of parody and flaunts that re-presentation in order to criticize that object in a humorous way".

8 "In every occurrence of verbal parody, the speaker conventionally makes use of four essential acts: (1) the intentional verbal re-presentation of the object of parody, (2) the flaunting of the verbal representation, (3) the critical act, and (4) the comic act" (Rossen-Knill y Henry, 1997, p. 723).

${ }^{9}$ En relación con la consideración de los evidenciales como marcas humorísticas, cfr. Ruiz Gurillo (2017).
} 
2) Se veían la luna y las primeras estrellas. Subí al palomar. Quizá no lo pensé de forma consciente, pero Tomás siempre me había dado buenos consejos, y tenía fama de ser un hombre cabal.

-Ahí va de ahí, cojona, que me pisas el sembrao - me dijo.

Eso en Teruel es la función fática que codificó Roman Jakobson: estableces un canal de comunicación. Nos quedamos un rato callados.

La referencia explícita a un concepto -y a un autor-tan relevantes desde el punto de vista lingüístico se ve nuevamente envuelta en marcas que hacen que se convierta, en el contexto, en humorística. De una parte, el "preámbulo" a esa referencia crea un ambiente que fácilmente puede asociarse a un momento romántico o íntimo: la noche, las estrellas, el palomar... El contraste lo genera la figura rústica de Tomás (con fama de hombre cabal; lo que haría esperable que su intervención fuera sabia) y su frase (que difícilmente podría entenderse como sabia, romántica o profunda). Sin embargo, Enrique la interpreta como un gesto benévolo, casi amable, hacia él (lo que supone una nueva actividad de autoimagen: a nadie le gusta sentirse rechazado) y ve en ello casi una actitud de acogida: establecer un canal de comunicación. El contraste entre los registros empleados por los personajes (el de Tomás, verbalizado; el de Enrique forma parte de sus pensamientos) también supone un indicador humorístico. Y la frase final refuerza el aspecto cómico del momento: se establece un canal de comunicación... para quedarse un rato callados.

3) Parecía claro que el mundo se terminaría antes que mi legislatura como alcalde. Es decir, el mundo tal como lo habíamos conocido. ¿Cómo afectaría a La Cañada el descalabro de la globalización, la desconfianza entre Estados Unidos y China, con los consiguientes efectos sobre las cadenas de producción y distribución? Estaba en el Pozo de las Eras y de repente encontré otro sentido al nombre: estaba ante el sumidero de la historia. El valor performativo del lenguaje te asalta cuando menos lo esperas. ¿Los nombres de los lugares podían acabar convirtiéndose en un acto de habla del destino, ajeno a la tipificación de J. L. Austin? ¿Qué quedaría de nuestro mundo después de la pandemia? El procés, pero ¿qué más?

Al margen de los contrastes humorísticos entre lo local y lo global de la primera parte del párrafo, queremos detenernos en la reflexión que el protagonista lleva a cabo sobre el nombre del "Pozo de las Eras", jugando con la polisemia (uno de los indicadores habituales empleados en el humor; cfr. Ruiz Gurillo, 2014, p. 152) del término "eras" como "espacio" y como "tiempo". Desde ahí, la referencia al valor performativo del lenguaje, así como a "un acto de habla del destino, ajeno a la tipificación de J. L. Austin", permite al narrador introducir de nuevo conceptos lingüísticos -concretamente, pragmáticos- en su discurso, lo que refuerza su autoimagen como una persona culta y reflexiva. Ello se muestra también en la concatenación de frases interrogativas con que termina el párrafo, y la respuesta local, cotidiana, que nuevamente genera el deseado efecto cómico ${ }^{10}-$ que se ofrece para la pregunta, mucho más profunda y global de "¿Qué quedaría de nuestro mundo después de la pandemia?".

10 “[...] la disociación de instancias enunciativas característica del acto humorístico facilita el tratamiento jocoso de aspectos cuya puesta en cuestión de manera seria podría chocar con la sensibilidad o las convicciones de los lectores [...]" (Vivero, 2006, p. 69). 


\section{Lenguaje vacío y tecnicismos: la parodia de la jerga política}

Como hemos señalado unos párrafos más arriba, Enrique Notivol ocupa el cargo de alcalde en La Cañada. En los textos que analizamos surgen también muestras de tecnicismos ${ }^{11}$-reales o supuestos- $\mathrm{y}$ otras expresiones rimbombantes, pero a menudo vacías de significado, vinculadas en numerosas ocasiones a muestras del discurso político. A continuación, veremos algunos ejemplos:

4) Esa tarde volví a casa preocupado.

Gobernanza multinivel, complejidad, gestión en red de la nueva incertidumbre y asunción activa del principio de la ignorancia, pensaba.

(7 de agosto de 2020)

5) Era necesario tener una reunión con los responsables sanitarios, así que fui a tomar café a casa de la médica. Coincidimos en que había que tener en cuenta las peculiaridades demográficas y económicas de La Cañada. Una era el porcentaje de población de riesgo, que por edad rondaba el $90 \%$. Muchos hombres, mineros jubilados... Si contabas que era más grave en los bebedores, estaría en el $95 \%$.

(8 de agosto de 2020)

6) Había mucho que pensar y decidir, casi me dieron ganas de volver a fumar. Tantos poderes para el ejecutivo. Vi que había un podcast sobre Hobbes de David Runciman, pensé en bajármelo donde hubiera un sitio con cobertura.

(8 de agosto de 2020)

En el primero de estos ejemplos, los sintagmas "gobernanza multinivel, complejidad, gestión en red" obedecen a un esquema que, como indica Marina Fernández Lagunilla (1999, p. 76), “[...] no responde a una exigencia informativa (como expresión de un contenido o un matiz nuevo ni siquiera a una búsqueda de mayor precisión conceptual), sino que es una forma de encarecer la misma idea cuando no de un lucimiento ornamental". A continuación, las expresiones "gestión en red de la nueva incertidumbre y asunción activa del principio de la ignorancia" son una forma alambicada, perifrástica, aparentemente técnica $\mathrm{y}$, por ende, eufemística, del mucho más llano, directo y coloquial "no sé qué hacer" (que, sin embargo, no resultaría "políticamente correcto" ni esperable en boca de un

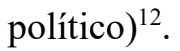

En el segundo ejemplo encontramos el término "reunión" y la perífrasis "responsables sanitarios" que inmediatamente después se concretan en "así que fui a tomar café a la casa de la médica". El contraste entre lo pedante del pensamiento y lo práctico de la acción (que en cierto modo recuerda al de "los eventos consuetudinarios que acontecen en la rúa" / "lo que pasa en la calle" machadiano) genera de nuevo un efecto cómico que a continuación se intensifica con la descripción de la "población de riesgo" a partir de las "peculiaridades demográficas y económicas" de La Cañada... para concluir que prácticamente toda la población es de riesgo.

11 “... el uso de los tecnicismos [...] se encuadra también en este deseo de conseguir una buena imagen, pues se busca un ennoblecimiento de la propia personalidad mediante el empleo de términos que verdaderamente [...], o al menos en apariencia [...], no son «de dominio público», sino que solo están al alcance de unos pocos y que, por tanto, aumentan la distancia entre quienes conocen su significado y quienes no, o entre quienes los emplean como rasgo de su pertenencia a un grupo y el resto" (Gómez Sánchez, 2006, p. 634).

${ }^{12}$ Como señalan Núñez Cabezas y Guerrero Salazar (2002, p. 31), "El político busca a menudo la expresión alambicada en detrimento de la frase más sencilla. De ahí que muchas expresiones de carácter perifrástico hayan cobrado vida y se hayan situado dentro de las favoritas de nuestra clase política”. 
En el tercer ejemplo, más allá de la actividad de autoimagen de considerarse a sí mismo "el ejecutivo", y del juego de palabras que se establece entre "tantos poderes para el ejecutivo" y los poderes del Estado (ejecutivo, legislativo y judicial), se llega de nuevo al golpe humorístico por la "distancia conceptual" que existe entre la posibilidad de aplicar, quizá, la elevada teoría que encierran las enseñanzas del politólogo y profesor de la universidad de Oxford D. Runciman al contexto de $\mathrm{La}$ Cañada, y la constatación que indica que, sin ir más lejos, la cobertura de la red para poder obtener ese podcast es más bien escasa en el entorno rural -y real- en el que se encuentra el protagonista ${ }^{13}$.

7) Aun así, se notaba una tranquilidad infrecuente. No es que La Cañada fuera Nueva York antes de la pandemia (aunque la latitud es la misma, 40,7 norte, por eso seguía con especial atención la gestión de Cassio y Cuomo), pero ya no se oían las mulas mecánicas por las mañanas, ni los tractores, o los vendedores ambulantes.

(9 de agosto)

En este caso, más allá de la referencia técnica a la latitud en la que se encuentra La Cañada (y su sorprendente, por no decir insólita, coincidencia con Nueva York), el efecto cómico -al que no es ajeno la actividad de autoimagen que se lleva a cabo- viene dado por la comparación que establece el protagonista entre su propia situación como alcalde y la gestión del Gobernador de Nueva York, Andrew Cuomo ${ }^{14}$, rematado por la referencia a elementos propios del mundo rural, como las mulas mecánicas o los tractores, impensables en la Gran Manzana.

8) Yo no quería ponerme paranoico, pero el número de detenciones y sanciones por habitante hacía pensar que La Cañada era más o menos Baltimore. Empecé a preguntarme si habría algo de racial profiling en esas actuaciones de la guardia civil: eran todos hombres blancos de más de sesenta años de edad, con boina, alpargatas y un gayato.

(9 de agosto)

En este último ejemplo -y más allá de que el cambio de código sea un indicador humorístico que puede encontrarse frecuentemente en discursos informales-, el tecnicismo del racial profiling (que, en tanto extranjerismo, da una apariencia aún "más elevada" al tecnicismo) genera el efecto cómico por el contraste que se produce entre la imagen que puede crearse en la mente del lector al leer ese sintagma (color de piel, edad, puede que incluso una determinada vestimenta, etc.) y la realidad de los sujetos a los que, en el contexto de La Cañada, se refiere: "eran todos hombres blancos de más de sesenta años de edad, con boina, alpargatas y un gayato". Ese absurdo es, por tanto, la estrategia aquí seguida, siempre que cuente tanto con el conocimiento compartido como con la complicidad del lector para la interpretación.

9) En vista de la situación, cuando empezó el confinamiento, me fui a casa de Lourdes, encima del bar, en vez de la de mi tía. Su ubicación era más céntrica, venía mejor para las emergencias que podía generar la crisis sanitaria.

\footnotetext{
13 "El hipster es aquel que tiene esa especie de plus que implica el acceso "inmediato" a los bienes culturales ya que vive en tal o cual barrio donde todo lo inunda de una experiencia de consumo 'a la última"” (Espinosa, 2017, p. 118).

${ }^{14}$ Consideramos, por similitud fonética, que "Cassio" pueda referirse a "Bill de Blasio", el alcalde de Nueva York.
} 
10) Mi antecesor como alcalde, y principal empresario local, dueño de la serrería, decía que en La Cañada teníamos el confinamiento más duro del mundo. Al parecer, me dijo mi tía, algunos comentaban que mi traslado a casa de Lourdes había roto las reglas del encierro y en todo caso era una cosa poco moral, aunque, como he explicado, se justificaba porque la casa de Lourdes estaba en un sitio mucho más céntrico y en una situación como la pandemia la rapidez de respuesta es esencial.

En estos dos ejemplos, y ante una situación que para algunos "era una cosa poco moral" (Enrique se ha ido a vivir a casa de su nueva novia), se presenta como un hombre precavido, que, como alcalde, toma medidas ante posibles eventualidades, justificando de ese modo su mudanza. Para salvar su imagen ante esos vecinos, se ampara en medidas racionales que respalden su decisión: es un sitio más céntrico y en una situación como la pandemia la rapidez de respuesta es esencial. En un lugar como La Cañada, es evidente que la justificación resulta poco creíble.

\section{Caracterización del habla rural: la ruptura del principio de cooperación y el empleo de frases hechas y términos tabú como recursos cómicos}

Ya nos hemos referido antes brevemente a la peculiar manera de hablar de Tomás; ofrecemos aquí ese diálogo completo para profundizar en el efecto cómico que sus respuestas generan por contraposición al "monólogo exterior" del hípster:

11) Se veían la luna y las primeras estrellas. Subí al palomar. Quizá no lo pensé de forma consciente, pero Tomás siempre me había dado buenos consejos, y tenía fama de ser un hombre cabal.

-Ahí va de ahí, cojona, que me pisas el sembrao-me dijo.

Eso en Teruel es la función fática que codificó Roman Jakobson: estableces un canal de comunicación. Nos quedamos un rato callados. El palomar era como un castillo. Entonces lo entendí: el pueblo era una ciudad sitiada, era como en la Edad Media. Eso me dio ánimos para preguntar.

- ¿Crees que esto va a reforzar o debilitar al populismo?

- Pues de todo habrá.

- Claro, es que piensas además que esto refuerza a los Estados y por tanto la idea de nación, pero a la vez también es algo global, entonces es un lío.

-Ya lo puedes decir.

-Y por otro lado, claro, dices, ¿y si es una llamada de atención de la naturaleza? ¿Una especie de advertencia? Como si la naturaleza se vengara de nuestras agresiones, de nuestra falta de sensibilidad, hemos trastocado de tal manera los ecosistemas...

- Te he dicho que no me pises el sembrao.

-Lo que está claro es que vivimos demasiado deprisa, estamos obsesionados por el dinero, el prestigio, el temor a quedarnos fuera, la visión del turismo se ha extendido a toda nuestra vida, la sensación de que hay que experimentar todo el tiempo... Igual esto es una especie de voz que dice: tranquilos, id más despacio.

-Chico, llevas media hora hablando y aún me dices que vamos con prisas.

Luego nos quedamos callados un rato más.

Como vemos, Tomás responde con frases breves, concisas y, sobre todo, "vacías" de contenido a las disquisiciones de Enrique. Hay interacción, pero no un auténtico diálogo: coloquialmente, podríamos decir que Tomás le da la razón a Enrique "como a los locos", le sigue la corriente, pero le importa más bien poco el torrente de palabras o las preguntas que Enrique se plantea. Desde el punto de vista 
pragmático, constatamos que no es precisamente el principio de cooperación ${ }^{15}$ el que se pone en marcha, sino que se violan al menos dos de las máximas de Grice (la de la cantidad y la de la relevancia), así como el principio de Informatividad de Levinson; en este caso, y como señala Ruiz Gurillo (2014, p. 150), "los efectos humorísticos se consiguen gracias a la infracción de los principios pragmáticos que gobiernan la comunicación".

Ya de entrada, la primera pregunta de Enrique -la única que formula, en realidad-genera hilaridad en el lector por lo "fuera de contexto", lo incongruente: es una pregunta que puede hacerse en un determinado entorno, quizá cotidiano entre personas con inquietudes políticas, pero parece poco esperable como forma de entablar conversación con un campesino más preocupado, como se ve en el diálogo, por las cuestiones prácticas ("Te he dicho que no me pises el sembrao" ${ }^{16}$ ). Los "claros" de Enrique también resultan marcas cómicas, pues en realidad más bien podría decirse que a medida que va hablando, menos claro parece su propio hilo de pensamiento. El remate lo ofrece Tomás cuando, a una de las últimas reflexiones de Enrique ("Igual esto es una especie de voz que dice: tranquilos, id más despacio") le responde "Chico, llevas media hora hablando y aún me dices que vamos con prisas".

También son un reflejo de habla popular algunas frases hechas ${ }^{17}$ o refranes que aparecen en los textos, siempre pronunciados por personajes distintos a Enrique Notivol: "Mal se le pone el ojo a la vaca" (dicho por "la tía Angelines" para dar a entender que algo malo va a ocurrir; en este caso, al igual que en el siguiente ejemplo, la palabra "tía" se emplea, no en el sentido de parentesco, sino en el de "tratamiento que se da a la persona entrada ya en edad", $D L E)$; "siempre viene uno de fuera a joder la marrana" (dicho por una de las vecinas del pueblo a la que se caracteriza como "la tía Michela"); "pero seréis zánganos, andar a cascarla" (dicho por la tía de Enrique -aquí sí, en sentido familiar, en tanto que hermana de su madre-). La frase se dirige a los amigos de Enrique, quienes llegan por sorpresa a La Cañada, y en ella también podemos señalar el uso de "andar" como vulgarismo, en lugar de "andad" y el empleo (con marca de coloquial en el $D L E$ de la RAE), de "cascarla" en lugar de "charlar". E igualmente habría que referirse al término "catatombe" que pronuncia otro de los vecinos ("el Tomás", con uso de artículo antes del nombre propio), y que podría interpretarse como una mezcla entre "cataclismo" y "hecatombe". Todos estos ejemplos subrayan igualmente el contraste entre el elaborado discurso de Enrique y el mucho más llano de sus vecinos, y contribuyen también a la comicidad del relato mediante esa caracterización lingüística de sus personajes.

Por otra parte, el empleo de términos sexuales (uno de los campos tradicionalmente considerados tabú y, por tanto, típicos de la interdicción) con un

\footnotetext{
${ }^{15}$ El principio de cooperación se infringe frecuentemente en mayor o menor grado en el humor verbal, en tanto que se trata de un tipo de comunicación non bona fide (cfr. Raskin y Attardo, 1994). El motivo por el que hacemos referencia específica a ello en este epígrafe (y no en apartados anteriores del artículo) es porque aquí se recoge por primera vez un diálogo entre los personajes y, por tanto, consideramos que queda mejor ilustrado.

${ }^{16}$ La pérdida de la "d" intervocálica se puede considerar un rasgo de habla coloquial (no solo en este territorio ficticio, sino también en otros lugares; cfr. Porroche, 2004).

17 "El humor fraseológico presentará ciertas particularidades que derivan del carácter convencionalizado del significado de las U[nidades] F[raseológicas]. A diferencia del humor "libre", el fraseológico constituye [...] una implicatura con alto grado de convencionalización, por lo que se aprende por el hablante como parte del significado global y no se genera ni se actualiza en el discurso como una implicatura conversacional particularizada" (Timofeeva, 2013, p. 137).
} 
efecto cómico también se hace presente en los textos que analizamos; el efecto además se amplía por el hecho de presentarse "con rima", al ser cantados y en forma de jota ( $\tan$ propia, por otra parte, de la idiosincrasia aragonesa; tengamos en cuenta que el territorio ficcionalizado de La Cañada se encuentra en Terue ${ }^{18}$ ), como vemos en el ejemplo siguiente:

12) Para poner en valor la importancia de la cultura, imprescindible para el desarrollo de una ciudadanía con sentido crítico, pensé en organizar sesiones de Instagram Live. Pero como la conexión en el pueblo es tan floja (uno de los proyectos que ha aplazado la covid-19, pero no me rindo), las jotas de Paca se oían más por la ventana que por los ordenadores o los móviles.

\section{Que se comió un pangolín aquel chino una mañana. \\ Desde entonces a mi novio \\ lo veo por la ventana.}

Fue emocionante el día que le contestó Rogelio desde el balcón de su casa, en la plaza:

\section{Aunque te pongas mascarilla no te creas que me inquieta: si no te veo la cara te conozco por las tetas.}

A pesar de que la letra tenía algunos aspectos problemáticos desde una perspectiva de género, fue un momento hermoso, casi mágico. Uno sentía claramente la comunidad amenazada, la sensación de que estábamos unidos, protegiéndonos unos a otros ${ }^{19}$

(9 de agosto de 2020)

En este fragmento no puede dejar de mencionarse tampoco el lenguaje afectado y pseudopolítico ("poner en valor la importancia de la cultura", "imprescindible para el desarrollo de una ciudadanía crítica" ${ }^{20}$ o la actividad de autoimagen ("pero no me rindo") que encontramos en su comienzo y que ya de por sí generan un efecto cómico por el contraste entre la hondura de esos deseos y el modo en que se llevarían a cabo ("sesiones de Instagram Live"; esto es, una red social más caracterizada por la imagen que por la palabra, tradicionalmente más asociada a la cultura y, por ende, a la capacidad crítica), y de lo que se podría inferir también la visión -velada y humorística- de lo que algunos puedan entender por cultura hoy. Ahora bien, es en las dos jotas donde, mediante el humor, se incluyen términos y conceptos que, expresados de manera "recta", podrían ser descorteses, bien por la cuestión del "tabú cultural" del alimento y de quién lo toma (y la visión negativa de Occidente hacia China que ello encierra), bien por la cuestión del "tabú sexual", al aparecer explícitamente un término que, en otros contextos, podría

\footnotetext{
${ }^{18}$ En otro momento del relato se refiere la llegada de los amigos de Enrique al pueblo ("Pensé que iban hacia el Planico de la Iglesia -donde habían aparcado la última vez que habían venido- y corrí hacia allí"). Esa denominación de "Planico", con el diminutivo en -ico, es, como indica Porroche, característico del discurso aragonés en su variante coloquial, "sin que haya diferencias en relación con los niveles socioculturales" (Porroche, 2004, pp. 216-217). También el término "azarollas" (fruto del serbal) que figura en el sexto de los relatos es un aragonesismo, e igualmente cabe señalar, en ese mismo relato, el empleo de la denominación "mosén" ("Título que se da a los clérigos en el antiguo reino de Aragón", $D L E$ ).

19 "En la utopía hipster de un barrio "sin clases y sin razas" todos somos felices miembros de las clases medias" (Espinosa, 2017, p. 120).

20 "Este nuevo teatro donde el hipster es elevado a la categoría del ciudadano ideal, gracias a sus hábitos cívicos y refinados, sería [...] también una noción política, donde se desarrolla un determinado vínculo social y se gesta un determinado sujeto político: el ciudadano" (Espinosa, 2017, p. 125).
} 
entenderse como disfemístico y resultar interdicto por no considerarse de buen gusto, pero que de este modo mueve a la hilaridad. En este sentido, hay una cierta "subversión" (cfr. Linares, 2019) que contribuye también a la caracterización de los personajes en torno a los cuales gira ese fragmento (tanto Paca como Rogelio son habitantes del pueblo), y que no deja de suponer cierta preocupación para Enrique desde el punto de vista de lo "políticamente correcto" en relación con la perspectiva de género (lo cual nuevamente contribuye a construir su imagen), si bien esa preocupación se ve rápidamente anulada por un sentimiento más fuerte, un tanto épico, de "cohesión", de "pertenencia al grupo" y, por tanto, se constituye en otra marca del discurso ideológico que identifica al protagonista (siempre dentro de las coordenadas humorísticas en el que se mueve todo el relato).

Hay una tercera jota en el relato correspondiente al 11 de agosto:

13) Una noche, en la hora de las jotas, Miguel Ángel cantó:

\section{Esto del coronavirus}

No pué empezar en Wuhan:

Seguro que andan por medio

el Soros y un catalán

(11 de agosto de 2020)

En este caso, más allá también de la imitación del habla vulgar en el acortamiento de "puede" por "pué", el efecto humorístico es evidente; y el procedimiento empleado para ello puede vincularse en parte a una actividad descortés ${ }^{21}$ (en tanto que se "culpa" a un catalán del coronavirus -además de a "el Soros"; el empleo de artículo delante del apellido remitiría también, como hemos señalado un poco más arriba, al habla popular-) y en parte a una actividad eufemística: no se nombra a un catalán en concreto, sino que se deja "abierto" y, por tanto, recae sobre el lector $-\mathrm{u}$ oyente de la jota, dentro del relato- la "responsabilidad" de inferir a qué catalán se refiere (suponiendo que se refiera a alguno en concreto).

Otro ejemplo en el que figura un término disfemístico, pero que contribuye igualmente al humor por el contexto en el que se genera, es el siguiente, que pertenece al relato que cierra la serie, publicado el 12 de agosto:

14) Lo sacamos, le dimos unas cucharadas y lo dejamos en la habitación. Silvina abrió una de las garrafas de licor de azarollas.

-Quiero plantar aquí en el jardín pero no sale nunca —dijo Silvina.

- No es fácil que agarre, no - respondió mi tío.

-Requiere un proceso químicamente complejo. Es mejor que la semilla esté blanca. La sumerges en agua una noche, luego la pones en una bolsa de congelar vigilando que no pierda humedad. En unos meses empiezan a germinar en la propia bolsa. Cuando la pones en tierra, hay que plantar la semilla no muy profundamente, es importante que la tierra sea caliza - dijo Aniuska.

- También puedes comerte el hueso y cuando lo cagues plantarlo.

- Sí, también valdría — dijo Aniuska tras reflexionar un momento.

-Es como siempre lo hemos hecho nosotros.

(12 de agosto de 2020)

A la científica explicación de Aniuska para que germinen las azarollas, una explicación detallada pero concisa, con elementos característicos del lenguaje

${ }^{21}$ Creemos, en cualquier caso, que este ejemplo continuaría siendo una muestra de humor con efecto positivo tal y como lo conceptualiza Alvarado (2012, pp. 16-17). 
técnico (por ejemplo, consejos e instrucciones para que el proceso sea un éxito), el tío de Enrique responde con un directo "También puedes comerte el hueso y cuando lo cagues plantarlo". Este rasgo de humor escatológico queda rematado por un "es como siempre lo hemos hecho nosotros" que apela a la tradición y de alguna manera "resta importancia" al proceso científico; es decir, hace que la "gramática parda" (o la sabiduría popular) prevalezca.

En el ejemplo anterior, Silvina es Silvina Domingo ("la gerente del Shanghái, el prostíbulo que hay en la carretera de la Venta, a unos ocho kilómetros del pueblo") y Aniuska, una de sus trabajadoras. Un poco antes, en ese mismo relato, se nos ha presentado a Aniuska, quien ha desarrollado un brebaje contra la enfermedad:

15) — ¿Lo habéis encontrado vosotras?

- Ha sido más cosa de Aniuska, las demás solo seguíamos sus instrucciones, como pinches.

No quería ser condescendiente ni prejuicioso, pero me costaba creer que la cura de la Covid-19 se hubiera encontrado en un puticlub de carretera. Al mismo tiempo, sabía que eso era ser condescendiente y prejuicioso, así que me intenté bloquear mis apriorismos. Hay que tomar la realidad tal como viene, estilo fenomenológico.

- ¿Una vacuna?

- No. Para eso necesitaríamos por lo menos un par de semanas más—dijo Aniuska, muy seria.

Pensé que Silvina siempre era original: con la de rusas que dicen que son descendientes de Anastasia y ella había dado con una que se creía Alexander Fleming. Ella detectó alguna vacilación. Me sentí culpable. ¿Dudaba porque eran mujeres? ¿Habría sido tan escéptico si, por ejemplo, los empleados de la serrería me hubieran dicho que habían encontrado la cura para la Covid-19 antes que los laboratorios y empresas farmacéuticas de Occidente? Quise pensar que habría mantenido el mismo rigor.

-Aniuska sabe de esto, Enrique. Estudió en la Universidad de Moscú. Luego empezó el doctorado en Oxford.

- ¿Y cómo has acabado aquí? - pregunté.

- No me gustaba la Universidad.

- ¿Por qué?

-Demasiada explotación.

(12 de agosto de 2020)

Más allá de la nueva actividad de autoimagen que Enrique lleva a cabo racionalizando sus sentimientos, "bloqueando sus apriorismos" e intentando mantener el mismo rigor al dudar de una posible cura para la Covid-19 en ese contexto con independencia de quiénes fueran sus descubridores, el efecto cómico del párrafo se genera tanto por la exposición del curriculum académico de Aniuska, como por el hecho de que no le gustara la Universidad como lugar de trabajo porque sentía que había "demasiada explotación": la paradoja que implicaría preferir ejercer la prostitución (otro tema tabú) a dedicarse a la carrera académica supondría otra transgresión que también podríamos considerar como humor subversivo (cfr. Linares, 2019).

\section{Conclusiones}

En este trabajo hemos analizado algunos de los recursos lingüísticos que se ponen en marcha en un conjunto de columnas literarias y que contribuyen a su caracterización como humorísticas. El empleo de recursos como hipérboles, contrastes, paradojas, términos tabú o las referencias explícitas a teorías lingüísticas contribuyen a caracterizar discursivamente a los personajes como pertenecientes al 
mundo rural frente al hípster procedente de la ciudad que, sin creerse abiertamente superior a sus vecinos -lo que le convertiría en un personaje antipático-, sí se considera bien formado (como muestran sus monólogos interiores y exteriores) y cree que puede poner ese conocimiento al servicio de los habitantes del lugar para aportarles una "visión nueva" y quizá más completa, cuando el hecho es que suele ser él quien aprende de los otros personajes, lo que contribuye también a crear esa imagen un tanto ingenua y despistada, indudablemente cómica. De este modo, estas columnas permiten reflexionar sobre la lengua desde una perspectiva tan seria como lúdica, y cumplen así con la máxima de Horacio de enseñar deleitando, un ideal al que no debiéramos renunciar.

\section{Referencias}

1. Alvarado Ortega, M. B. (2012). Una propuesta de estudio para el humor en la conversación coloquial. Estudios lingüísticos de la Universidad de Alicante, 26, pp. 728. DOI: https://doi.org/10.14198/ELUA2012.26.01

2. Casals Carro, M. - J. (2000). La columna periodística: de esos embusteros días del ego inmarchitable. Estudios sobre el mensaje periodístico, 6, pp. 31-51.

3. Espinosa Zepeda, H. (2017). Hipster o la lógica de la Cultura urbana bajo el Capitalismo. Estudios sobre las culturas contemporáneas, 23(46), pp. 111-134.

4. Fernández Lagunilla, M. (1999). La lengua en la comunicación política I: El discurso del poder. Madrid: Arco Libros.

5. Gómez Sánchez, M. ${ }^{\text {a }}$ E. (2006). Cortesía y eufemismo: los sustitutos eufemísticos en la prensa y la defensa de la propia imagen. En Blas, J. L., Velando, M. y Casanova, M. (Coords.), Discurso y sociedad: contribuciones al estudio de la lengua en contexto social (pp. 625-636). Castellón: Universidad Jaume I.

6. Hernández Flores, N. (2006). Actividades de autoimagen, cortesía y descortesía: tipos de actividades de imagen en un debate televisivo. En Blas, J. L., Velando, M. y Casanova, M. (Coords.), Discurso y sociedad: contribuciones al estudio de la lengua en contexto social (pp. 637-648). Castellón: Universidad Jaume I.

7. Le Grand, E. (2020). Representing the middleclass 'hipster': Emerging modes of distinction, generational oppositions and gentrification. European Journal of Cultural Studies, 23(2) 184-200. DOI: https://doi.org/10.1177/1367549418772168

8. León Gross, T. (2005). La columna y lo literario como valor periodístico, Ínsula, 703704, pp. 5-8.

9. Linares Bernabéu, E. (2019). La conceptualización lingüística del tabú en el discurso humorístico subversivo. E-Scripta Romanica, 7, pp. 77-96. DOI:

https://doi.org/10.18778/2392-0718.07.07

10. López Hidalgo, A. (2008). El concepto estético de la columna periodística en la obra de Manuel Alcántara. En León Gross, T. y Gómez Calderón, B. (Eds), El artículo literario: Manuel Alcántara (pp. 151-170), Málaga: Universidad.

11. López Pan, F. (2011). El articulista-personaje como estrategia retórica en las columnas personales o literarias. Anàlisi, 41, pp. 47-68.

12. Núñez Cabezas, E. A. y Guerrero Salazar, S. (2002). El lenguaje político español, Madrid. Cátedra.

13. Porroche Ballesteros, M. (2004). Estudio de una elaboración humorística del español hablado en Aragón. En Enguita Utrilla J. M. a (Coord.), Jornadas sobre la variación lingüística en Aragón a través de los textos (pp. 205-225), Zaragoza: Institución Fernando el Católico.

14. Porroche Ballesteros, M. (2012). Oralidad y escritura en las columnas de opinión de la prensa zaragozana actual. Archivo de filología aragonesa, 68, pp. 231-252.

15. Raskin, V. y Attardo, S. (1994). Non-literalness and non-bona-fîde in language. An approach to formal and computational treatments of humor. Pragmatics \& Cognition, 2(1), pp. 31-69. DOI: https://doi.org/10.1075/pc.2.1.02ras

16. Ruiz de la Ciera, Ma C. (2012). La transfuncionalidad de los discursos: discurso periodístico y discurso literario. En Comunicación y riesgo. III Congreso internacional de la Asociación Española de Investigación en Comunicación (pp. 111). Tarragona: Universidad Rovira y Virgili. 
17. Rossen-Knill, D. F. y Henry, R. (1997). The pragmatics of verbal parody. Journal of Pragmatics, 27, pp. 719-752. DOI: https://doi.org/10.1016/S0378-2166(96)00054-9

18. Ruiz Gurillo, L. (2014). Infiriendo el humor. Un modelo de análisis para el español. CLAC. Círculo de lingüistica aplicada a la comunicación, 59, pp. 148-162. DOI: https://doi.org/10.5209/rev_CLAC.2014.v59.46712

19. Ruiz Gurillo, L. (2017). El evidencial con humor entra. Acerca de su uso en los monólogos humorísticos. Normas, 7(2), pp. 5-18. DOI:

https://doi.org/10.7203/Normas.v7i2.9218

20. Ruiz Gurillo, L. (2019). El humor como hecho pragmático en español. Revista de investigación lingüistica, 22, pp. 183-198. DOI: https://doi.org/10.6018/ril.381161

21. Timofeeva, L. (2013). En torno al tratamiento lexicográfico de la fraseología humorística. RLA. Revista de Lingüistica Teórica y Aplicada, 51(1), pp. 127-151. DOI: https://doi.org/10.4067/S0718-48832013000100007

22. Vigara Tauste, A. M.a (1994). El chiste y la comunicación lúdica: lenguaje y praxis. Madrid. Ediciones Libertarias.

23. Vivero García, M. a D. (2006). Procedimientos discursivos y formas de humor en las columnas periodísticas francesas y españolas. Sintagma, 18, pp. 67-80. 